\title{
Tracking speakers' false beliefs: is theory of mind available earlier for word learning?
}

Article

Accepted Version

Houston-Price, C., Goddard, K., Seclier, C., Grant, S. C., Reid, C. J.B., Boyden, L. E. and Williams, R. (2011) Tracking speakers' false beliefs: is theory of mind available earlier for word learning? Developmental Science, 14 (4). pp. 623-634. ISSN 1363-755X doi: https://doi.org/10.1111/j.14677687.2010.01003.x Available at https://centaur.reading.ac.uk/21685/

It is advisable to refer to the publisher's version if you intend to cite from the work. See Guidance on citing.

To link to this article DOI: http://dx.doi.org/10.1111/j.1467-7687.2010.01003.x Publisher: Blackwell Publishing

All outputs in CentAUR are protected by Intellectual Property Rights law, including copyright law. Copyright and IPR is retained by the creators or other copyright holders. Terms and conditions for use of this material are defined in the End User Agreement.

\section{www.reading.ac.uk/centaur}

\section{CentAUR}


Central Archive at the University of Reading

Reading's research outputs online 
Tracking speakers' false beliefs:

Is Theory of Mind available earlier for word learning?

\author{
Carmel Houston-Price \\ Kate Goddard \\ Catherine Séclier \\ Sally C. Grant \\ Caitlin J.B. Reid \\ Laura E. Boyden \\ Rhiannon Williams
}

RUNNING HEAD: Tracking speakers' false beliefs

Acknowledgements: We would like to thank the preschoolers who participated in these studies and four anonymous reviewers for their helpful suggestions about an earlier draft of this paper.

Address correspondence to: Dr C. Houston-Price, School of Psychology \& Clinical Language Sciences, University of Reading, Earley Gate, Whiteknights, Reading, RG6 6AL, UK. Email: c.houston-price@ reading.ac.uk 


\begin{abstract}
Happé and Loth (2002) describe word learning as a 'privileged domain' in the development of a theory of mind. We test this claim in a series of experiments based on the Sally-Anne paradigm. Three- and four-year-old children's ability to represent others' false beliefs was investigated in tasks that required the child either to predict the actions of a protagonist in a story or to learn the meaning of a new word used by the protagonist. Experiment 1 replicated previous findings of better performance in a false belief word-learning task compared to a false belief action-prediction task. However, systematic manipulation of the task parameters in Experiments 2 and 3 revealed that this performance discrepancy disappeared when tasks were equated in their "referential pull" (Perner, Rendl \& Garnham, 2007). We conclude that the notion of a precocious theory of mind for word learning is not required to explain dissociations in performance on false belief tasks.
\end{abstract}




\section{Introduction}

In classic tests of false belief awareness (Baron-Cohen, Leslie \& Frith, 1985; Perner, Leekam \& Wimmer, 1987; Wimmer \& Perner, 1983), children typically fail to demonstrate an understanding that others' beliefs may be different to their own, or indeed false, until their fourth or fifth year (Wellman, Cross \& Watson, 2001). Success at such false belief tasks is seen by many as a key milestone in the child's development of a 'theory of mind' - the attribution of mental states such as beliefs, thoughts, desires and intentions to oneself and others. Reports of precocious false belief understanding in highly similar tasks that additionally comprise a word-learning component (Carpenter, Call \& Tomasello, 2002; Happé \& Loth, 2002) therefore deserve attention.

Happé and Loth (2002) directly compared preschool children's performance on the Sally-Anne transfer task (Baron-Cohen et al., 1985), a popular assessment of false belief understanding, with their performance on a task that required children to use their understanding of a protagonist's false belief to identify the referent of a novel word. In the Sally-Anne task, the child is told a story using two puppets. Sally (the protagonist) hides an object in a basket and, after she has left, Anne moves the object from the basket to a box. When Sally returns, the child must identify that she has a false belief about the location of the object and determine the likely consequences of this belief for her searching behaviour. Happé and Loth devised a word-learning situation that was similar to the Sally-Anne task, except that in this task Anne replaces Sally's object with a second object after Sally has left. When Sally returns, she picks up the container and says, "There's a modi in this box!" The child must use the character's false belief about the contents of the box to identify which of the two objects is the 'modi'. Happé and Loth reported that $87 \%$ of 3- to 5-year-olds successfully tracked the character's false belief to identify which object was the 'modi' in the word-learning task, while only $36 \%$ could use the character's false belief to predict where she would look in the standard action-prediction task.

Using a paradigm borrowed from the word-learning literature, Carpenter et al. (2002) reported a similar discrepancy between the two varieties of false belief task. In their false belief word- 
learning task, children saw an experimenter place an object into a container before leaving the room. While she was absent, the child saw the object being switched with a second object. The experimenter then returned and exclaimed that she wanted to get the 'dax' or 'toy' out of the container. When both objects were subsequently presented to the child, the majority of 3-year-olds selected the object that had originally been in the container as the referent, rather than the object that was in the container during the experimenter's attempts to open it, suggesting that children were aware of the experimenter's lack of knowledge of the switch. In contrast, only a minority of children passed more traditional false belief tasks, including the Sally-Anne action-prediction task.

Happé and Loth (2002) claim that such dissociations in performance indicate that communication (and, more specifically, vocabulary acquisition) has a privileged status in the child's development of a theory of mind. They suggest that the large discrepancy in children's performance on the two false belief tasks might be explained by the existence of multiple theory of mind mechanisms that develop at different rates for different purposes (Sperber, 2000; Sperber \& Wilson, 2002; Wilson, 2000), with a communication sub-module emerging at a younger age than an action-prediction sub-module.

Support for Happé and Loth's (2002) views might be found in evidence that infants as young as 15 or 18 months appear to have a basic awareness that others have motivational mental states, such as intentions and desires (Meltzoff, 1995; Repacholi \& Gopnik, 1997), which they can use to learn words. For example, on hearing someone utter a new word, an infant will check the speaker's direction of attention or expression of desire towards an object in order to map the word to the appropriate referent (Baldwin, 1991, 1993; Baldwin, Markman, Bill, Desjardins, Irwin \& Tidball, 1996; Tomasello, Strosberg \& Akhtar, 1996). In Tomasello et al.'s (1996) study, when an experimenter expressed her desire to find the 'gazzer' and proceeded to reject the first object she found and react with satisfaction towards a second object, 18-month-olds successfully attached the word to the intended referent. In a second study, infants of the same age were able to identify the referent of a new word even though it was out of sight: An experimenter's expression of intent to 
find the 'toma' and her attempts to open a container were sufficient for infants to interpret the word as the label for the object hidden inside.

While these studies do not reveal the full-blown 'belief-desire theory of mind' that is needed to succeed on false belief tasks, they demonstrate that infants are able to draw on a sensitivity to others' desires and intentions in order to learn new words. If such evidence were found only in the domain of vocabulary development, and not elsewhere, this might be considered support for the view that theory of mind emerges precociously for communication purposes (Happé \& Loth, 2002; Sperber \& Wilson, 2002). Recent developments in the methodology available for investigating mental state reasoning in toddlers under two or three years have, however, produced evidence of very early employment of false belief understanding across a range of task structures, including tests of action-prediction. For example, in an adaptation of the Sally-Anne transfer task, Southgate, Senju and Csibra (2007) found that 25-month-old infants showed anticipatory looks towards the location in which they expected the protagonist to search, revealing an awareness of the protagonist's false belief about the target's location. Other researchers have found evidence of sensitivity to belief states in infants as young as 13 or 15 months using the violation of expectation paradigm (Onishi \& Baillargeon, 2005; Surian, Caldi \& Sperber, 2007; but see Perner \& Ruffman, 2005). The fact that early signs of theory of mind reasoning are now being found in both the action-prediction and word-learning domains weighs against Happé and Loth's (2002) view that false belief understanding may be available earlier for purposes of communication.

The stark discrepancy between preschool children's performance on Happé and Loth's (2002) and Carpenter et al.'s (2002) two varieties of false belief task therefore remains to be explained. What are the alternatives to the multiple mechanism account? One possibility is that children's superior performance in the word-learning task, relative to the action-prediction task, is attributable to subtle, but important, differences in the situations set up by the two types of task. Previous research has demonstrated that performance on false belief action-prediction tasks is affected by a range of manipulations of task structure and the cognitive load this imposes (e.g. 
Carlson, Moses \& Hix, 1998; Lewis, Freeman, Hagestadt \& Douglas, 1994; Leslie, German \& Polizzi, 2005; Leslie \& Polizzi, 1998; Siegal \& Beattie, 1991; Sullivan \& Winner, 1993; Wellman et al., 2001). Therefore, in this article, we examine whether the dissociation in children's performance on the two types of false belief task holds up in the face of a series of systematic manipulations of task structure.

First, we explore the possibility that children's considerably better performance in Happé and Loth's (2002) false belief word-learning task, relative to the false belief action-prediction task, is due to gratuitous differences in the designs of the two tasks. The two tasks differed in a number of ways other than their contrasting goals of action prediction versus word learning, including the number of objects the child had to track (one in the action-prediction task, two in the wordlearning task) and the number of hiding locations (two in the action-prediction task, one in the word-learning task). In addition, while false belief understanding can be variously assessed by asking about the protagonist's behaviour, knowledge or thoughts about the transfer (Baron-Cohen et al., 1995; Roth \& Leslie, 1998), Happé and Loth asked a single question following the actionprediction task (“Where will Sally look for her ball?”) and four questions following the wordlearning task ("Which one is the modi?", "Is this one the modi?", etc), making it difficult to directly compare children's performance on the two tasks. Experiment 1 of this paper therefore sought to replicate Happé and Loth's key findings using experimental tasks that were more closely matched in their designs. Specifically, each of our tasks required the child to track the movement of two objects between two locations and assessed the child's false belief understanding by means of three questions, one of which was the key action-prediction or word-learning question.

We also examine the possibility that children's better performance on Happé and Loth's (2002) false belief word-learning task is an artefact of the protagonist's greater association with the target object in this task. Recall that, in the word-learning task, Sally carries in object A and hides it in a location from which it is subsequently moved. She returns and labels the object hidden in this location as the 'modi'. When the child is subsequently asked to identify the 'modi', the child might 
draw on the character's false belief to work out that she intended to name the object that had been removed, rather than the object that was in the labelled location. However, given that Sally has never come into contact with object B, the child might alternatively (and quite reasonably) assume that Sally intended to name her own toy. Thus, a child might solve the word-learning task without any awareness of Sally's false belief, by associating Sally with object A at the outset, and attributing Sally's label to object A when later asked to identify the 'modi'. (See Southgate et al., 2007, for further discussion of this point).

It is worth noting that the word-learning literature would not necessarily predict that children should operate in such a mechanistic way. Tomasello and colleagues have demonstrated that twoyear-old children attend carefully to a speaker's intention to label an object in order to identify a new word's reference, rather than simply mapping the word to an available referent by association (Akhtar, Carpenter \& Tomasello, 1996; Tomasello \& Barton, 1994; Tomasello et al., 1996). Nevertheless, given that Carpenter et al.'s (2002) false belief word-learning task suffers from a similar confound, it is important to rule out the possibility that children's high level of success in the word-learning task is due to their knowledge of the protagonist's prior association with the target object rather than their awareness of the protagonist's false belief. Our Experiment 2 investigated this issue by comparing performance on two false belief tasks in which the protagonist's associations with the target and non-target objects (and locations) were equated.

The third explanation of the performance discrepancy explored in this article is the role played by the young child's 'reality bias' (Mitchell, 1994; Mitchell \& Lacohée, 1991). At least part of children's difficulty with location-change false belief tasks lies in the need to inhibit or override the 'pull of the real' exerted by the actual location of the target. That is, when asked, "Where will Sally look for her ball?", the child is biased to respond by indicating the location where Sally

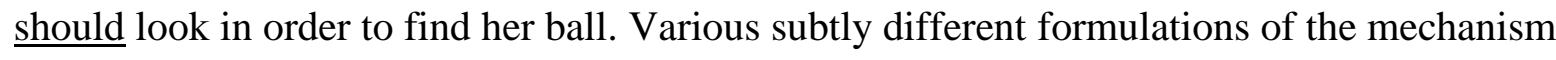
underlying this bias have been offered. For example, some see the child as operating with a positive bias to focus on the physical reality of the world (Mitchell, 1994; Mitchell \& Lacohée, 
1991), while others suggest that their difficulty lies in the need to suppress their own knowledge in order to take another's perspective (Birch \& Bloom, 2003; Leslie, Friedman \& German, 2004; Leslie \& Polizzi, 1998). A similar proposal is that children's poor performance reflects the underdevelopment of domain-general executive processes, such as inhibition (Carlson \& Moses, 2001; Carlson et al., 1998; Russell, 1997; Russell, Saltmarsh \& Hill, 1999); this view is supported by the strong correlations that have been identified between success on false belief tasks and measures of executive function that require the child to inhibit conflicting, prepotent responses (Carlson \& Moses, 2001). One final suggestion is that children may be overly challenged by the verbal nature of false belief tasks; before they have processed the whole of the question, "Where will Sally look for her ball?", they may have prematurely responded to "Where...?" by indicating where the ball is (Csibra \& Southgate, 2006).

While the precise cause of the child's reality bias remains unknown, the consequence of operating with such a bias is clear: Children who are not yet able to pass location-change false belief tasks do not choose randomly between the two response options but are more likely to select the incorrect location, where the ball 'really' is. This pattern of behaviour can be seen in the below-chance proportion of participants who selected the correct location in Happé and Loth's (2002) action-prediction task (36\%). Researchers have attempted to overcome this response bias by devising adaptations of the Sally-Anne task that remove the 'pull of the real', typically by eliminating the target from the scene before the child is asked where the protagonist will search. For example, after Sally has hidden her ball and left the scene, Anne might switch Sally's ball to a second location, but then change her mind and leave the scene, taking the ball with her. In this design, the child must still retrieve Sally's false belief about the location of her ball in order to answer the test question successfully, but there is no longer a salient 'reality' to inhibit at the same time. Such manipulations provide a significant boost to children's performance: In Wellman et al.'s (2001) meta-analysis of 178 studies of typically-developing children's false belief 
understanding, the 'real presence' of the target at the time of questioning was the strongest predictor of children's performance, after age.

Might the reality bias be responsible for the performance discrepancy reported by Happé and Loth (2002) and Carpenter et al. (2002)? Perner, Rendl and Garnham (2007) point out that it is only in the action-prediction tasks reported by these authors that the child experiences a 'referential pull' towards the actual location of the hidden toy, the incorrect answer. Children's superior performance in the word-learning task might, therefore, result from the lack of a comparable pull towards the incorrect answer (the non-target object) in this task; when the child is asked, "Which do you think is the modi?", there is no a priori knowledge about the 'modi' to be inhibited. Our Experiment 3 interrogates the possibility that dissociations in children's performance on the two tasks might disappear when the referential pull exerted in each task is equated.

In line with Happé and Loth (2002) and Carpenter et al. (2002), we included a 'true belief word-learning task' in each study, in addition to the two false belief tasks. The true belief task presents an identical scenario to the false belief word-learning task except that, in this story, the protagonist Sally observes Anne switching the objects around, removing the child's need to represent Sally's false belief. We included the true belief task to control for the possibility that children might succeed in the false belief word-learning task by means of a strategy other than attention to the protagonist's false belief. For example, in Experiment 1, a child might select the target referent as the 'modi' simply because this object was introduced to the story first. Adopting the same strategy would lead to failure in the true belief task because, in this case, the object that is introduced first is not the object that is labelled. Any evidence of better performance in the false belief word-learning task compared to the true belief word-learning task would therefore suggest that children are operating with a learning strategy that does not involve representing the protagonist's false belief. 


\section{Experiment 1}

The first experiment aimed to replicate the study reported by Happé and Loth (2002) while equating each of their tasks in terms of the number of objects the child had to track, the number of hiding locations available, and the number of questions asked after each story.

\section{Method}

\section{Participants}

Forty-two children were recruited through six nurseries in the South East of England. A pilot study involving children aged three, four and five years found performance to be at ceiling among the oldest group; thus, only three- and four-year-olds were recruited for the main study. The final sample included 21 three-year-olds ( 12 girls $\& 9$ boys; mean age $=3 ; 6.20$; range $=3 ; 0.0-3 ; 11.27$ ) and 21 four-year-olds ( 10 girls $\& 11$ boys; mean age $=4 ; 4.27$; range $=4 ; 0.0-4 ; 9.7$ ). Children came from a range of socio-economic backgrounds and ethnicities.

\section{Materials}

Props were hand-made, including two colourful cloth puppets ('James' \& 'Lizzie') and two painted cardboard boxes. A key and a bracelet were used as objects in a memory pre-test and a ball and a toy car were used as objects in the action-prediction task. Four Plasticene objects with distinctive but unfamiliar shapes were used as referents in the word-learning tasks (objects A, B, C \& D in Table 1).

\section{Procedure}

Children were tested individually in a quiet area at their nursery. All participants underwent a memory pre-test in which a key was placed in a box, removed and replaced with a bracelet. The child was asked "What is in the box now?" and "What was in the box first of all?" All participants answered both questions correctly.

Children completed all three tasks (false belief action-prediction, false belief word-learning, and true belief word-learning) in one of three counter-balanced orders (FBWL, TBWL, FB; 
TBWL, FB, FBWL; or FB, FBWL, TBWL). The key events of each story and the questions asked afterwards are shown in Table 1.

Each task required the child to watch two puppets act out a story while the experimenter narrated from a script. In each story, Lizzie enters, shows the child her object and hides it in one of two locations. She then either leaves the scene (in the two false belief tasks) or stays and watches (in the true belief task). James enters with a second toy and shows it to the child. He then takes Lizzie's toy out of the first location and places it in the second location, before hiding his own toy in the first location. There are therefore two objects and two locations to track in each task. In the false belief action-prediction task, Lizzie returns to the scene and exclaims that she wants her toy, and the child is asked where she will look for it first. In the two word-learning tasks, Lizzie picks up the box where she hid her toy and says that there is a "flibble" or "zeboo" in the box. The child is then asked to select the "flibble / zeboo" from among the two potential referents.

\section{$<$ INSERT TABLE 1 ABOUT HERE >}

The key events of each story and the deceptive element of the false belief tasks were emphasised to ensure that these were salient. After each story had been told, the child was asked three questions to assess their understanding of the protagonist's false (or true) belief and their ability to use this knowledge to predict the character's actions or to learn a new word. In each case, the child was asked a 'look' question about where one might look for the target object, a 'know' question about the protagonist's knowledge of the transfer, and a 'think' question about the identity or location of the target. The key question in the action-prediction task was the 'look' question, while the 'think' questions were the key word learning questions (see Table 1).

\section{Results and Discussion}

Preliminary chi-square analyses found no effects of the order in which the three tasks were completed (all $p s>.05)$ and the data were therefore collapsed across this factor for subsequent analyses. Figure 1 presents the proportion of children who responded correctly to each key question. It can be seen that the older children generally performed better than the younger 
children and that, at both ages, more children succeeded on the word-learning tasks than on the action-prediction task. To explore these differences in task performance we entered the number of children who answered the key question correctly versus incorrectly into a 2 (age) x 3 (task) x 2 (response) log-linear analysis. There was a main effect of age, $G^{2}(1)=7.52, p=.006$, caused by the better performance of the older children, and an interaction between age and task, $G^{2}(7)=15.8$, $p=.027$. Chi-square analyses showed that the interaction was caused by the older group performing marginally better than the younger group on the action-prediction task, $\chi^{2}(1)=3.50, p=.061$, and on the false belief word-learning task, $\chi^{2}(1)=3.86, p=.050$, but not on the true belief wordlearning task, $\chi^{2}(1)=1.00, p=.32$. Importantly, the log-linear analysis also revealed a main effect of task, $G^{2}(2)=7.26, p=.027$. While children performed equally well on the two word-learning tasks, $\chi^{2}(1)=.06, p=.82$, fewer children answered the key question correctly on the actionprediction task than on either the false belief word-learning task, $\chi^{2}(1)=4.81, p=.028$, or the true belief word-learning task, $\chi^{2}(1)=5.85, p=.016$.

\section{< INSERT FIGURE 1 ABOUT HERE >}

As in Happé and Loth (2002) and Carpenter et al. (2002), we found that children performed significantly better in the false belief word-learning task than in the false belief action-prediction task, even when the two tasks were more closely matched in their designs. This pattern of behaviour fits with the view that children are better able to draw on their knowledge of a protagonist's false belief when it is required to interpret the meaning of a new word than when it is needed to anticipate the character's behaviour. However, before the data can be interpreted as providing support for Happé and Loth's (2002) claim that children's word learning profits from access to a precocious 'communicative theory of mind', several further potential explanations of children's better performance in the word-learning task must be ruled out.

Experiment 2 examines the role played by the protagonist's prior association with the target object in the false belief word-learning task. In Experiment 1 (and in the studies on which it was based), a child might have selected the target object as the 'flibble' simply because it was Lizzie 
who named the 'flibble' and because the target object was known to belong to Lizzie from the outset. It is worth noting that the pattern of performance children displayed across the three tasks of Experiment 1 is inconsistent with the application of this type of learning strategy. If children had selected the object with which Lizzie was more strongly associated in the true belief wordlearning task (object C), they would have failed this task; the correct answer was object D, which was not Lizzie's toy. Yet, children performed as well on this task as they did on the false belief word-learning task. Moreover, if children had employed a similar strategy in the false belief action-prediction task, selecting the only location with which the protagonist had had prior contact, they would have been successful at the task. Again, this was not the case. Nevertheless, Experiment 2 directly explores the possibility that children's high level of success in the false belief word-learning task depends on the protagonist's prior association with the target object. In this study, we equated the protagonist's association with the target and non-target objects (and locations) in each task, by having Lizzie introduce both objects to the scene. This manipulation would be expected to eliminate the performance discrepancy observed in Experiment 1, if this discrepancy was due to the protagonist's strong association with the target object in the false belief word-learning task.

We made one further change to the design of Experiment 2, to rule out the possibility that the order in which test questions were asked facilitated performance on the word learning tasks of Experiment 1. Despite our endeavours to match the questions asked after each story as closely as possible, the logical ordering of questions led the key question in the word-learning tasks - about which novel object was the 'flibble'/ 'zeboo' - to be the third question asked, while the key question came first in the action-prediction task (see Table 1). It is therefore possible that the two questions that preceded the key question in the word-learning tasks served to remind children about the current location and previous location-change of the target object, boosting performance in these tasks. In Experiment 2, we ruled out this potential confound by asking only a single test question after each story. 


\section{Experiment 2}

\section{Method}

\section{Participants}

Ninety-six three- and four-year-old children were recruited from two nurseries in the South East of England. Four three-year-olds failed the memory pre-test and were excluded from testing for this reason. The final sample therefore included 44 three-year-olds (17 girls \& 27 boys; mean age $=$ $3 ; 6.17$; range $=3 ; 0.11-3 ; 11.24$ ) and 48 four-year-olds (19 girls $\& 29$ boys; mean age $=4 ; 3.26$; range $=4 ; 0.1-4 ; 11.12$ ). Children came from a range of socio-economic backgrounds and ethnicities.

\section{Materials}

Six colourful puppets were hand-made, two for each task. A decorated metal tin and sequinned box were used as hiding locations. A plastic horse and toy car were used as objects in the memory pretest, and a key and a ball were used in the action-prediction task. Four objects that were expected to be unfamiliar to children were used as objects in the word-learning tasks (a speaker jack, vacuum cleaner part, set of Allan keys \& a fairy light).

\section{Procedure}

Testing took place individually in a quiet area at the child's nursery. All participants underwent a memory pre-test in which the car was placed in a box, removed and replaced with the horse. The child was asked "What is in the box now?" and "What was in the box first of all?" All four-yearolds and all but four of the three-year-olds answered both questions correctly and proceeded with the experiment.

Children completed all three tasks (false belief action-prediction, false belief word-learning \& true belief word-learning) with the order of tasks fully counter-balanced between participants. As in Experiment 1, each task required the child to watch two puppets act out a story while the experimenter narrated the story from a script. Two different puppets were used in each task, and 
the allocation of novel objects to each word-learning task, the target object and location of the target in each task were fully counter-balanced between children. As before, the experimenter made the transformations salient and emphasised the deceptive element of the false belief tasks, to ensure that children attended to the important events in each story. After each story had been told, children were asked a single question to assess their understanding of the protagonist's false (or true) belief. The key events of each story and the questions asked afterwards are described in Table 2, with the key differences between Experiments 1 and 2 highlighted.

\section{$<$ INSERT TABLE 2 ABOUT HERE >}

As can be seen in Table 2, there are two important differences between these tasks and those of Experiment 1. Most importantly, the protagonist brings in both objects at the start of each story and places each of them in a different location, ensuring that her association with each object (and location) is equivalent. If children's better performance in the false belief word-learning task compared to the action-prediction task in Experiment 1 was caused by the protagonist's stronger association with the target object in the word-learning task, equating her association with the two

objects should eliminate the discrepancy in task performance. Second, children were asked only the key question following each task, to rule out the possibility that performance might be facilitated by prior questioning about the events that had taken place.

\section{Results and Discussion}

Figure 1 presents the proportion of children who responded correctly to each key question. It can be seen that while performance tended to be lower in this experiment, the pattern of the data is broadly similar to that seen in Experiment 1. That is, children were more likely to select the target object in the false belief word-learning task than they were to indicate the correct location in the false belief action-prediction task. To explore children's performance across the three tasks, we entered the number of children who responded correctly versus incorrectly into a 2 (age) x 3 (task) x 2 (response) log-linear analysis. There was no main effect of age in this study, $G^{2}(1)=.06$, $p=.81$, and no significant interaction between age and task, $G^{2}(7)=12.7, p=.079$. However, there 
was a significant main effect of task, $G^{2}(2)=6.4, p=.041$. While children performed equally well on the two word-learning tasks, $\chi^{2}(1)=1.08, p=.30$, and on the false belief action-prediction and true belief word-learning tasks, $\chi^{2}(1)=2.19, p=.14$, fewer children succeeded on the false belief action-prediction task than on the false belief word-learning task, $\chi^{2}(1)=6.28, p=.012$.

These findings again support the view that children are better able to reveal their knowledge of a character's false belief when this knowledge is required to interpret the meaning of a new word than when it is needed to predict the character's actions. The elimination of the protagonist's stronger association with the target object in the false belief word-learning task did not reduce the discrepancy in performance on the two false belief tasks; children again displayed superior performance on the false belief word-learning task. The lack of any influence of the hypothesised character-target associations is corroborated by the relatively poor performance of the older group on the true belief task; performance on this task should have been facilitated by removing the protagonist's stronger association with the non-target object, if children were using such a strategy.

In order to statistically compare performance in Experiments 1 and 2, we carried out three separate 2 (study) x 2 (age) x 2 (response) log-linear analyses, one for each task. For the false belief action-prediction task, there was a significant main effect of age, $G^{2}(1)=4.0, p=.046$, but no main effect of study, $G^{2}(1)=.08, p=.77$, or interaction between study and task, $G^{2}(4)=5.0, p=.29$. The same pattern was found for the false belief word-learning task: There was a main effect of age, $G^{2}(1)=4.2, p=.04$, but no effect of study, $G^{2}(1)=.76, p=.38$, or interaction between study and task, $G^{2}(4)=6.2, p=.18$. For the true belief word-learning task, we found a significant effect of study, $G^{2}(1)=3.86, p=.050$, no effect of age, $G^{2}(1)=1.2, p=.27$, and an interaction between study and age that approached significance, $G^{2}(4)=8.52, p=.074$. Further exploration revealed that the four-year-old children were more successful on the true belief task in Experiment 1 than in Experiment $2, \chi^{2}(1)=6.98, p=.008$, while the behaviour of the three-year-olds across the two experiments was indistinguishable, $\chi^{2}(1)=.002, p=.97$. 
These analyses confirm that the changes we made to the design of Experiment 2 served only to hinder the older group's performance on the true belief task. Given that the elimination of the protagonist's association with the non-target object should have facilitated, rather than hindered, performance on this task, the most likely explanation of the older group's poorer performance on the true belief task of Experiment 2 lies in the changes we made to the order of test questions. That is, this group may have benefited from the two probe questions that preceded the key wordlearning questions in Experiment 1, which may have served to remind them about the preceding events. More importantly, these analyses reveal that the changes we made to the design of Experiment 2 had no impact on children's behaviour on the two false belief tasks. The discrepancy in children's performance on the two false belief tasks cannot, therefore, be attributed to differences in the protagonist's prior association with the target object or location.

Experiment 3 explores one further potential explanation of children's better performance on the false belief word-learning task. In the action-prediction tasks used in Happé and Loth (2002), Carpenter et al. (2002), and Experiments 1 and 2 of this article, a correct response required the child to overcome the 'referential pull' exerted by the actual location of the target object (Perner et al., 2007). In contrast, the word-learning tasks did not require participants to inhibit their desire to reveal the target in the same way; when children were asked to identify the referent of the novel word, there was no reason for an a priori bias towards either of the two novel objects. Thus, better performance in the false belief word-learning task compared to the action-prediction task might be attributable to differences in children's baseline tendency to select the target object or location.

In Experiment 3, we eliminated the referential pull from the action-prediction task by removing both objects from their hiding places before asking children the test question (see Southgate et al., 2007, for a similar procedure). If children's apparent precocity in using false belief understanding for word learning is a result of their bias towards reality in the action-prediction task, elimination of this bias should simultaneously eradicate the performance discrepancy. Children were asked only a single test question following each story, as in Experiment 2. 


\section{Experiment 3}

\section{Method}

\section{Participants}

Fifty-nine three- and four-year-old children were recruited from three nursery schools in the South East of England and South Wales. The sample included 25 three-year-olds (12 girls \& 13 boys; mean age $=3 ; 6.26 ;$ range $=3 ; 1.7-3 ; 11.30)$ and 34 four-year-olds $(18$ girls $\& 16$ boys; mean age $=$ $4 ; 4.0 ;$ range $=4 ; 0.4-4 ; 11.25)$. Children came from a range of socio-economic backgrounds and ethnicities.

\section{Materials}

Two colourful puppets, similar to those used in the previous studies, were hand-made. A decorated cardboard box and metal tin were used as hiding locations. A small teddy and a ball were used in the action-prediction task. Four novel objects were constructed from unfamiliar household items to be used in the word-learning tasks (objects A, B, C \& D in Table 3).

\section{Procedure}

Children were tested individually in a quiet area at the child's nursery. No memory pre-test was included in this study, as virtually all participants passed the pre-test in previous studies.

Children completed all three tasks (false belief action-prediction, false belief word-learning \& true belief word-learning) with the order fully counter-balanced between participants. As in previous experiments, each task required the child to watch two puppets act out a story while the experimenter narrated a story from a script and the key events and transformations were emphasised by means of enthusiastic narration of the story. The target object and location of the target in each task were fully counter-balanced between children. After each story had been told, children were asked a single question to assess their understanding of the protagonist's false (or true) belief. The key events of each story and the questions asked afterwards are described in Table 3, with differences from Experiment 1 highlighted. 
As can be seen in Table 3, the two word-learning tasks were identical to those of Experiment 1, except that only a single question was asked after each story, as in Experiment 2. The crucial manipulation was made to the action-prediction task; this differed from the false belief task of Experiment 1 in that, after the 'naughty' character has changed the location of the protagonist's toy, he takes both toys away with him. Thus, when the protagonist returns to search for her toy, the child should experience no 'referential pull' towards either location, meaning that the baseline tendency to select the correct and incorrect location should be equal.

\section{Results and Discussion}

Figure 1 presents the proportion of children who responded correctly to each question. Unlike previous experiments, the data show no evidence of better performance in the false belief wordlearning task compared to the action-prediction task; indeed, for the four-year-old group, the pattern is reversed. Removal of the 'pull of reality' therefore appears to have facilitated performance on the action-prediction task.

To explore children's performance across the three tasks, we entered the number of children who responded to each question correctly versus incorrectly into a 2 (age) x 3 (task) x 2 (response) log-linear analysis. There were no main effects of age, $G^{2}(1)=.08, p=.77$, or task, $G^{2}(2)=2.66$, $p=.26$, and no interaction between them, $G^{2}(7)=4.46, p=.73$. Thus, there were no significant differences in children's performance across the three tasks.

These findings suggest that the discrepancy in children's performance in the two false belief tasks of Experiment 1 is best explained in terms of a referential pull being exerted in Experiment 1 but not in the current study. However, to draw the strong conclusion that this task manipulation is responsible for children's better performance in the action-prediction task of Experiment 3, statistical comparison of the data from the two studies is required. As before, we carried out three separate 2 (study) x 2 (age) x 2 (response) log-linear analyses, one for each task. For the false belief action-prediction task, there was a significant main effect of age, $G^{2}(1)=4.94, p=.026$, a main effect of study, $G^{2}(1)=4.62, p=.032$, and an interaction between age and study, $G^{2}(4)=10.1$, 
$p=.039$. Overall, children were more likely to succeed on the action-prediction task in Experiment 3 than in Experiment 1, and this pattern was more evident for three-year-olds, $\chi^{2}(1)=3.49, p=$ .062 , than for four-year-olds, $\chi^{2}(1)=1.04, p=.31$. For the two word-learning tasks, there were no effects of age or study (all $p s>1$ ). These analyses confirm that the removal of the referential pull in Experiment 3 significantly boosted children's performance on the action-prediction task, to the extent that the discrepancy in performance between the false belief word-learning and actionprediction tasks was eliminated.

\section{Discussion}

The experiments reported in this article suggest that what has previously been described as precocious theory of mind ability in the word-learning domain (Happé \& Loth, 2002) is better explained in terms of fundamental differences in the designs of the tasks used to tap children's false belief understanding. While we were able to replicate previous evidence of superior performance on a false belief task that required children to track a speaker's intention to label a novel object compared to a more traditional action-prediction task (Experiments $1 \& 2$ ), we were also able to eliminate this performance discrepancy by equating the challenges posed by the two types of task (Experiment 3). Specifically, our findings suggest that evidence of precocious false belief understanding in the word-learning domain is an artefact of the unbalanced referential pull of the false belief tasks employed in previous research.

The susceptibility of young children to the pull of reality is an established influence on their performance in the traditional Sally-Anne object-transfer task and its variants (Birch \& Bloom, 2003; Csibra \& Southgate, 2006; Happé \& Loth, 2002; Mitchell, 1994; Mitchell \& Lacohée, 1991; Wellman et al., 2001; Wimmer \& Perner, 1983). The step-like increase in correct performance that is reported to occur at about four or five years of age owes as much to the below-chance performance of children who fail the task as it does to the above-chance performance of those who pass. That is, when asked, "Where will Sally look for her ball?", children younger than four years are often drawn to indicate the location where the ball is currently hidden, the wrong answer. 
Perner et al. (2007) pointed out that this conflict between the child's knowledge of where the protagonist should look to find the object she desires and the correct response to the question about where she will look is not a feature of the false-belief word-learning tasks used in previous research (Carpenter et al., 2002; Happé \& Loth, 2002). In the word-learning scenario, there is no comparable pull towards the incorrect response when the child is offered the two novel objects and asked which is the 'modi'. Indeed, there is no reason for children to select either object unless they understand that the protagonist intended to label the object that she believed to be in the box at the time of labelling. Perner et al. therefore suggest that the children who took part in Carpenter et al.'s and Happé and Loth's studies might have appeared to demonstrate precocious theory of mind understanding in their false belief word learning tasks because 'failing' participants were more likely to select the target referent by chance in this task. Our studies confirm that the elimination of the referential pull from the action-prediction task leads children to perform as well on this task as they do on the false belief word-learning task. In sum, children's apparent precocity at interpreting false belief in service of word learning appears to be an empirical artefact, caused by the confounding pull of reality in the standard action-prediction task.

It is interesting to note that efforts to control for the young child's impulsive reaction to reality through removing the target object prior to asking the false belief test question can be traced back to Wimmer and Perner (1983), who found that such a manipulation boosted the performance of a group of 4- and 5-year-olds. However, questions remain about how and why children's performance in the action-prediction task is supported by this manipulation (see Birch \& Bloom, 2003; Carlson \& Moses, 2001; Carlson et al., 1998; Csibra \& Southgate, 2006; Leslie, Friedman \& German, 2004; Leslie \& Polizzi, 1998; Mitchell, 1994; Mitchell \& Lacohée, 1991; Russell, 1997; Russell, Saltmarsh \& Hill, 1999). Our experiments were not designed to discriminate between the various theoretical accounts of children's difficulty in overcoming the lure of the object's current location in the action-prediction task; as a consequence, the data do not speak to the nature of the mechanism that underlies the facilitation afforded by the removal of the test object from the scene. 
However, it is important to consider whether children's relative success in our final study, in which we employed this type of manipulation, might have arisen through some other means than their ability to attribute a false belief to the protagonist.

First, can we consider a task without the pull of reality as a bona fide false belief task? Given that the original formulations of most popular false belief tasks require the child to override conflicting perceptual or knowledge-based cues in order to answer the test question (Baron-Cohen et al., 1985; Perner et al., 1987; Wimmer \& Perner, 1983), is the elimination of such conflict too fundamental a change to the nature of the task? In our view, the requirement to inhibit the lure of the position of the target object in response to the test question is an additional, rather than essential, task component. False belief understanding refers to the ability to simultaneously hold a representation of the true state of affairs alongside a representation of another person's false belief about the situation. If a child can reason, "Sally thinks the ball is in Box A. The ball is not in Box A. But Sally thinks it is in Box A, so that is where she will look", the child can be said to show false belief understanding. Thus, it is not important whether the object is in Box B or has been removed from the scene, as long as the true state of affairs at the time of questioning differs to the content of the protagonist's false belief. We would therefore argue that performance on an actionprediction task in which the pull of reality has been eliminated is a valid index of the child's ability to represent false belief.

Given this position, do our data unambiguously attest to false belief understanding in our three- and four-year-old participants? While it is clear that removing the referential pull in Experiment 3 significantly improved children's performance in the action-prediction task, it is not clear that children in both age groups performed above chance on this task. Binomial analyses reveal that, while children as a group selected the target location at a rate above chance, this effect was driven by the success of the older group, and the younger group performed at chance. We cannot, therefore, conclude that the responses of our three-year-old participants were based on representations of the protagonist's false belief. How, then, can we account for the significant 
improvement we saw in this group's performance when the pull of reality was removed? One possibility is that three-year-olds base their answers on their understanding of the protagonist's knowledge, rather than the protagonist's belief. That is, if a child realises that Sally's object has been moved without her knowledge, but is not yet able to represent her false belief about its location, the child might reason that Sally could look in either hiding location, and randomly choose between the two locations as a result. When there is no bias to select the object's current hiding place (the non-target location), the proportion of children who randomly select the target location will be greater, leading to an apparent increment in performance. In line with Perner et al.'s (2007) arguments relating to differential baseline response tendencies, it is likely that differences in our younger group's baseline tendency to select the non-target in the two variants of the task explains their better performance when the pull of reality was removed. On the other hand, while our older group may also have benefited from the removal of the lure to the non-target location in Experiment 3, there can be no doubt that the four-year-olds' above-chance performance reflects this group's ability to represent the protagonist's false belief.

Our findings therefore corroborate Perner et al.'s (2007) concern that the confounding factor of referential pull should be controlled in future research into theory of mind understanding. That a seemingly minor event in the action-prediction task - removing objects from their final locations before asking children where the protagonist will look - should result in such a significant increment in performance confirms the importance of the detail of the design in theory of mind tasks. These studies therefore lend weight to a growing body of research demonstrating that extraneous task demands may mask children's competence in the domain of false belief understanding. While we found no evidence of significantly above-chance performance in our three-year-old group, recent research suggests that signs of theory of mind awareness may be detectable in even younger children if sufficiently sensitive methodologies are employed, such as anticipatory looking time or violation of expectation (Onishi \& Baillargeon, 2005; Southgate et al., 2007; Surian et al., 2007). Those who adhere to the view that a fundamental conceptual change 
occurs at around four years of age question whether these recent studies genuinely demonstrate an understanding of false belief (Perner \& Ruffman, 2005), pointing out that implicit measures of understanding, such as eye gaze duration, map poorly onto children's responses to explicit questions in false belief tasks (Clements \& Perner, 1994; Ruffman, Garnham, Import \& Connelly, 2001). However, such challenges are based on the premise that traditional measures of false belief understanding provide a 'gold standard' against which new tests of theory of mind awareness must be proven. Bloom and German (2000) draw attention to the fact that tasks such as the Sally-Anne task are, in fact, very difficult for children, requiring a host of skills over and above the ability to represent another person's beliefs. They conclude that young children's generally poor performance on this task is at odds with widespread evidence of their ability to represent mental states in other domains, and they question the utility of the paradigm for exploring the development of children's representational capacity.

Of course, Bloom and German's (2000) concerns apply equally to the tasks employed in our studies. Indeed, the measures we took to match the three tasks on the numbers of objects and locations to be tracked (and to control the protagonist's association with each object and location in Experiment 2) are likely to have increased the difficulty of our tasks still further. The additional burden posed by these controls may, in part, explain the generally low level of performance we observed on the true belief word-learning task. In none of our experiments did performance in this task significantly exceed performance in the false belief word-learning task. And only in Experiment 1, when children were asked two 'reminder' questions about the transfer events of the story before they were asked the key word-learning question, did both age groups perform above chance on the true belief task. These findings might simply indicate that this task failed to engage children's interest sufficiently; previous research has shown that children are more drawn to stories that involve trickery and deception (Sullivan \& Winner, 1993; Wellman et al., 2001), both of which were lacking in the true belief task. However, children's performance on this task is also consistent with the possibility that the complexity that arises when one introduces the necessary 
controls to such tasks leaves the paradigm at the limits of three- and four-year-olds' capacity. In order to answer questions about the age of emergence of complex theory of mind representational abilities, and the developmental stages at which children are able to employ these in different domains, researchers might do well to pursue new methodologies.

Adaptations of the traditional Sally-Anne task proved invaluable, however, in the current set of studies. Systematic manipulation of the parameters of the task revealed that, by eliminating the pull of reality in the action-prediction task, the performance discrepancy between this task and a similar false belief word-learning task was simultaneously eradicated. The data therefore speak to recent theoretical claims regarding the nature of the module employed for theory of mind activities. Happé and Loth (2002) argued that children's superior ability to draw on theory of mind understanding in order to acquire new words demonstrates that communication forms a 'privileged domain' in the child's theory of mind. Their claim was not merely that children are able to call upon a theory of mind mechanism earlier for purposes of language and communication than in support of action prediction. Rather, Happé and Loth evoked Sperber and Wilson's (2002) 'multiple theory of mind mechanism' hypothesis, which argues for a qualitative distinction in the mechanisms required to infer false belief in the two tasks. Sperber and Wilson proposed the existence of two independent sub-modules in the pragmatic (theory of mind) module, one dedicated to communication and one for predicting non-communicative behaviour. While such a view fits well with reports of dissociations between the two varieties of false belief task, it is clearly undermined by evidence that these dissociations depend on a non-essential task component. In sum, there is no support in our data for the view that there is an advanced theory of mind mechanism for word learning. 


\section{References}

Akhtar, N., Carpenter, M. \& Tomasello, M. (1996). The role of discourse novelty in early word learning. Child Development, 67, 635-645.

Baldwin, D. (1991). Infants' contribution to the achievement of joint reference. Child Development, $62,875-890$.

Baldwin, D. (1993). Early referential understanding: Infants' ability to understand referential acts for what they are. Developmental Psychology, 29, 832-843.

Baldwin, D.A., Markman, E.M., Bill, B., Desjardins, R.N., Irwin, R.N. \& Tidball, G. (1996). Infants' reliance on a social criterion for establishing word-object relations. Child Development, $67,3135-3153$.

Baron-Cohen, S., Leslie, A. \& Frith, U. (1985). Does the autistic child have a 'theory of mind'? Cognition, 21, 6-46.

Birch, S.A.J. \& Bloom, P. (2003). Children are cursed: An asymmetric bias in mental-state attribution. Psychological Science, 14, 283-286.

Bloom, P. \& German, T.P. (2000). Two reasons to abandon the false belief task as a test of theory of mind. Cognition, 77, B25-B31.

Carlson, S.M. \& Moses, L.J.(2001). Individual differences in inhibitory control and children's theory of mind. Child Development, 72, 1032-1053.

Carlson, S.M., Moses, L.J. \& Hix, H.R. (1998). The role of inhibitory control in young children's difficulties with deception and false belief. Child Development, 69, 672-691.

Carpenter, M., Call, J. \& Tomasello, M. (2002). A new false belief test for 36-month-olds. British Journal of Developmental Psychology, 20, 393-420.

Clements, W.A. \& Perner, J. (1994). Implicit understanding of belief. Cognitive Development, 9 , 377-397.

Csibra, G. \& Southgate, V. (2006). Evidence for infants' understanding of false beliefs should not be dismissed. Trends in Cognitive Sciences, 10, 4-5. 
Happé, F. \& Loth, E. (2002). 'Theory of mind' and tracking speakers' intentions. Mind \& Language, 17, 24-36.

Leslie, A.M., Friedman, O. \& German, T.P. (2004). Core mechanisms in 'theory of mind'. Trends in Cognitive Sciences, 8, 528-533.

Leslie, A.M., German, T.P. \& Polizzi, P. (2005). Belief-desire reasoning as a process of selection. Cognitive Psychology, 50, 45-85.

Leslie, A.M. \& Polizzi, P. (1998). Inhibitory processing in the false belief task: Two conjectures. Developmental Science, 1, 247-253.

Lewis, C., Freeman, N., Hagestadt, C. \& Douglas, H. (1994). Narrative access and production in preschoolers' false belief reasoning. Cognitive Development, 9, 397-424.

Meltzoff, A.N. (1995).Understanding the intentions of others: Re-enactment of intended acts by 18 month-old children. Developmental Psychology, 31, 838-850.

Mitchell, P. (1994). Realism and early conception of mind: A synthesis of phylogenetic and ontogenetic issues. In C. Lewis \& P. Mitchell (Eds.), Children's early understanding of mind: Origins and development. Hove, East Sussex: Lawrence Erlbaum Associates.

Mitchell, P. \& Lacohée, H. (1991). Children's early understanding of false belief. Cognition, 39, 107-127.

Onishi, K.H. \& Baillargeon, R. (2005). Do 15-month-old infants understand false beliefs? Science, $308,255-258$.

Perner, J. Leekam, S.R. \& Wimmer, H. (1987). Three-year-old's difficulty with false belief: The case for a conceptual deficit. British Journal of Developmental Psychology, 5, 125-137.

Perner, J., Rendl, B. \& Garnham, A. (2007). Objects of desire, thought and reality: Problems of anchoring discourse referents in development. Mind \& Language, 22, 475-513.

Perner, J. \& Ruffman, T. (2005). Infants' insight into the mind: How deep? Science, 308, 214-216.

Repacholi, B.M. \& Gopnik, A. (1997). Early reasoning about desires: Evidence from 14- and 18month-olds. Developmental Psychology, 33, 12-21. 
Roth, D. \& Leslie, A. (1998). Solving belief problems: Towards a task analysis. Cognition, 66, 1-31.

Ruffman, T. Garnham, W., Import, A. \& Connelly, D. (2001). Does eye gaze indicate implicit knowledge of false belief? Charting transitions in knowledge. Journal of Experimental Child Psychology, 80, 201-224.

Russell, J. (1997). Autism as an executive disorder. Oxford: Oxford University Press.

Russell, J., Saltmarsh, R. \& Hill, E. (1999). What do executive factors contribute to the failure on false belief tasks by children with autism? Journal of Child Psychology \& Psychiatry, 40, 859-868.

Siegal, M. \& Beattie, K. (1991). Where to look first for children's knowledge of false beliefs. Cognition, 38, 1-12.

Southgate, V., Senju, A., \& Csibra, G. (2007). Action anticipation through attribution of false belief by 2-year-olds. Psychological Science, 18, 587-592.

Sperber, D. (2000). Metarepresentations in an evolutionary perspective. In D. Sperber (Ed.), Metarepresentations: A multidisciplinary perspective (pp. 117-137). New York: Oxford University Press.

Sperber, D. \& Wilson, D. (2002). Pragmatics, modularity and mind-reading. Mind \& Language, 17, 3-23.

Sullivan, K. \& Winner, E. (1993). Three-year-olds' understanding of mental states: The influence of trickery. Journal of Experimental Child Psychology, 56, 135-148.

Surian, L., Caldi, S. \& Sperber, D. (2007). Attribution of beliefs by 13-month-old infants. Psychological Science, 18, 580-586.

Tomasello, M. \& Barton, M. (1994). Learning words in non-ostensive contexts. Developmental Psychology, 30, 639-650.

Tomasello, M., Strosberg, R. \& Akhtar, N. (1996). Eighteen-month-old children learn words in nonostensive contexts. Journal of Child Language, 23, 157-176.

Wellman, H.M., Cross, D. \& Watson, J. (2001). Meta-analysis of theory-of-mind development: The truth about false belief. Child Development, 72, 655-684. 
Wilson, D. (2000). Metarepresentation in linguistic communication. In D. Sperber (Ed.),

Metarepresentations: A multidisciplinary perspective (pp. 411-448). New York: Oxford University Press.

Wimmer, H. \& Perner, J. (1983). Beliefs about beliefs: Representation and constraining function of wrong beliefs in young children's understanding of deception. Cognition, 13, 103-128. 


\begin{tabular}{|c|c|c|}
\hline $\begin{array}{c}\text { False Belief } \\
\text { Action-prediction Task }\end{array}$ & $\begin{array}{c}\text { False Belief } \\
\text { Word-learning Task }\end{array}$ & $\begin{array}{c}\text { True Belief } \\
\text { Word-learning Task }\end{array}$ \\
\hline $\begin{array}{l}\text { Lizzie shows the child her ball } \\
\& \text { puts it in the orange box. }\end{array}$ & $\begin{array}{l}\text { Lizzie shows the child object } \mathbf{A} \& \\
\text { puts it in the orange box. }\end{array}$ & $\begin{array}{l}\text { Lizzie shows the child object } \mathbf{C} \& \\
\text { puts it in the orange box. }\end{array}$ \\
\hline Lizzie leaves the room. & Lizzie leaves the room. & Lizzie stays in the room. \\
\hline $\begin{array}{l}\text { James enters \& shows the child } \\
\text { his car. }\end{array}$ & $\begin{array}{l}\text { James enters \& shows the child } \\
\text { object B. }\end{array}$ & $\begin{array}{l}\text { James enters \& shows the child } \\
\text { object } D \text {. }\end{array}$ \\
\hline $\begin{array}{l}\text { James removes Lizzie's ball } \\
\text { from the orange box, puts it in } \\
\text { the green box, puts his car in the } \\
\text { orange box \& closes both lids. }\end{array}$ & $\begin{array}{l}\text { James removes object A from the } \\
\text { orange box, puts it in the green } \\
\text { box, puts object B in the orange } \\
\text { box \& closes both lids. }\end{array}$ & $\begin{array}{l}\text { James removes object } \mathbf{C} \text { from the } \\
\text { orange box, puts it in the green } \\
\text { box, puts object } \mathbf{D} \text { in the orange } \\
\text { box \& closes both lids. }\end{array}$ \\
\hline Lizzie returns. & Lizzie returns. & Lizzie has been watching. \\
\hline $\begin{array}{l}\text { Lizzie says, "I want to play } \\
\text { with my ball". }\end{array}$ & $\begin{array}{l}\text { Lizzie picks up the orange box \& } \\
\text { says, "Here's the flibble all safe } \\
\text { and sound. The flibble is in this } \\
\text { box. Shall we see the flibble? } \\
\text { Let's take out the flibble". }\end{array}$ & $\begin{array}{l}\text { Lizzie picks up the orange box \& } \\
\text { says, “Here's the zeboo all safe } \\
\text { and sound. The zeboo is in this } \\
\text { box. Shall we see the zeboo? } \\
\text { Let's take out the zeboo". }\end{array}$ \\
\hline $\begin{array}{l}\text { The child is asked: } \\
\text { Where will Lizzie look for } \\
\text { her ball first? } \\
\text { \{Answer = Orange Box\} } \\
\text { Does Lizzie know that James }\end{array}$ & $\begin{array}{l}\text { The child is asked: } \\
\text { Where would you look first for th } \\
\text { Does Lizzie know James has mov } \\
\text { Both novel objects are placed in fro } \\
\text { Which do you think is the flibbl }\end{array}$ & $\begin{array}{l}\text { flibble/ zeboo? } \\
\text { ther flibble/ zeboo? } \\
\text { zeboo? }\end{array}$ \\
\hline $\begin{array}{l}\text { has moved her ball? Where } \\
\text { does Lizzie think the ball is? }\end{array}$ & $\{$ Answer $=$ Object $A\}$ & $\{$ Answer $=$ Object $D\}$ \\
\hline
\end{tabular}

Table 1: The key events of each story and the questions asked afterwards in Experiment 1.

Differences between tasks and the key question asked following each task (and answers to these) are shown in bold. 


\begin{tabular}{|c|c|c|}
\hline $\begin{array}{c}\text { False Belief } \\
\text { Action-prediction Task }\end{array}$ & $\begin{array}{c}\text { False Belief } \\
\text { Word-learning Task }\end{array}$ & $\begin{array}{c}\text { True Belief } \\
\text { Word-learning Task }\end{array}$ \\
\hline $\begin{array}{l}\text { Sally enters with a ball \& a key, } \\
\text { places the ball in the box \& the } \\
\text { key in the bucket. }\end{array}$ & $\begin{array}{l}\text { Mary enters with novel objects A } \\
\text { \& B, places object A in the box } \\
\text { \& object B in the bucket. }\end{array}$ & $\begin{array}{l}\text { Jim enters with novel objects C \& } \\
\text { D, places object C in the bucket } \\
\text { \& object D in the box. }\end{array}$ \\
\hline Sally leaves the room. & Mary leaves the room. & Jim stays in the room \& watches. \\
\hline $\begin{array}{l}\text { Anne enters \& switches the ball } \\
\text { \& key around. }\end{array}$ & $\begin{array}{l}\text { Tom enters \& switches objects A } \\
\text { \& B around. }\end{array}$ & $\begin{array}{l}\text { Lucy enters \& switches objects C } \\
\text { \& D around. }\end{array}$ \\
\hline $\begin{array}{l}\text { Sally returns \& says, "I want to } \\
\text { play with my ball". }\end{array}$ & $\begin{array}{l}\text { Mary returns, touches the box \& } \\
\text { says, "Here's the modi all safe and } \\
\text { sound. The modi is in this box. } \\
\text { This is where my modi is. Shall } \\
\text { we see the modi?" }\end{array}$ & $\begin{array}{l}\text { Jim touches the box \& says, } \\
\text { "Here's the blicket all safe and } \\
\text { sound. The blicket is in this box. } \\
\text { This is where my blicket is. Shall } \\
\text { we see the blicket?" }\end{array}$ \\
\hline $\begin{array}{l}\text { The child is asked: } \\
\text { Where will Sally look for her }\end{array}$ & \multicolumn{2}{|c|}{$\begin{array}{l}\text { The two objects are placed in front of the child \& the child is asked: } \\
\text { Show me the modi / blicket! Which one is the modi / blicket? }\end{array}$} \\
\hline $\begin{array}{l}\text { ball first? } \\
\{\text { Answer }=\text { Box }\}\end{array}$ & $\{$ Answer $=$ Object $A\}$ & $\{$ Answer $=$ Object $C\}$ \\
\hline
\end{tabular}

Table 2: The key events of each story and the questions asked afterwards in Experiment 2.

Differences between the events of Experiments 1 and 2 are shown in bold. 


\begin{tabular}{|c|c|c|}
\hline $\begin{array}{l}\text { False Belief } \\
\text { Action-prediction Task }\end{array}$ & $\begin{array}{c}\text { False Belief } \\
\text { Word-learning Task }\end{array}$ & $\begin{array}{l}\text { True Belief } \\
\text { Word-learning Task }\end{array}$ \\
\hline $\begin{array}{l}\text { Jane shows the child her teddy \& } \\
\text { places it in the box. }\end{array}$ & $\begin{array}{l}\text { Jane shows the child novel object } \\
\text { A \& places it in the box. }\end{array}$ & $\begin{array}{l}\text { Jane shows the child novel object } \\
\text { C \& places it in the box. }\end{array}$ \\
\hline Jane leaves the room. & Lizzie leaves the room. & Jane stays in the room. \\
\hline $\begin{array}{l}\text { Ben enters \& shows the child his } \\
\text { ball. }\end{array}$ & $\begin{array}{l}\text { Ben enters \& shows the child } \\
\text { novel object B. }\end{array}$ & $\begin{array}{l}\text { Ben enters \& shows the child } \\
\text { novel object D. }\end{array}$ \\
\hline $\begin{array}{l}\text { Ben removes Jane's teddy from } \\
\text { the box, puts it in the tin, puts his } \\
\text { ball in the box \& closes both } \\
\text { lids. }\end{array}$ & $\begin{array}{l}\text { Ben removes object A from the } \\
\text { box, puts it in the tin, places object } \\
\text { B in the box \& closes both lids. }\end{array}$ & $\begin{array}{l}\text { Ben removes object } \mathrm{C} \text { from the } \\
\text { box, puts it in the tin, puts object } \\
\text { D in the box \& closes both lids. }\end{array}$ \\
\hline $\begin{array}{l}\text { Ben is called away, and takes } \\
\text { both toys with him. }\end{array}$ & & \\
\hline Jane returns. & Jane returns. & Jane has been watching. \\
\hline $\begin{array}{l}\text { Jane says, "I want to play with } \\
\text { my teddy". }\end{array}$ & $\begin{array}{l}\text { Jane taps the box \& says, "Here's } \\
\text { the wug all safe and sound. The } \\
\text { wug is in this box. There's a wug } \\
\text { in here". }\end{array}$ & $\begin{array}{l}\text { Jane taps the box \& says, "Here's } \\
\text { the modi all safe and sound. The } \\
\text { modi is in this box. There's a } \\
\text { modi in here". }\end{array}$ \\
\hline $\begin{array}{l}\text { The child is asked: } \\
\text { Where will Jane look for her }\end{array}$ & \multicolumn{2}{|c|}{$\begin{array}{l}\text { The two objects are placed in front of the child } \& \text { the child is asked: } \\
\text { Which do you think is the modi/ wug? }\end{array}$} \\
\hline $\begin{array}{l}\text { teddy first? } \\
\qquad \text { Answer }=\text { Box }\}\end{array}$ & $\{$ Answer $=$ Object $A\}$ & $\{$ Answer $=$ Object $D\}$ \\
\hline
\end{tabular}

Table 3: The key events of each story and the questions asked afterwards in Experiment 3.

Differences between the events of Experiments 1 and 3 are shown in bold. 


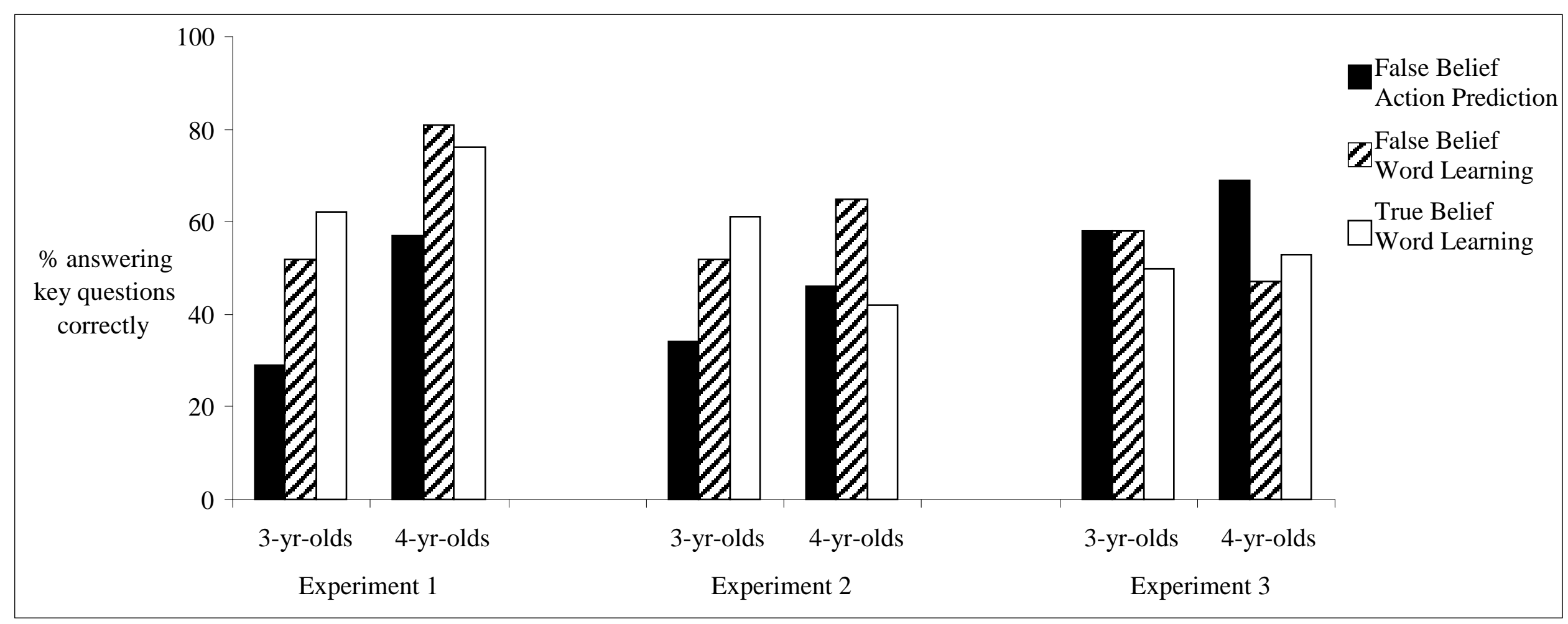

Figure 1. Percentage of children who answered the key questions correctly in each task in Experiments 1, 2 and 3. 